\title{
Combined Edge Segment Texture Analysis for the Detection of Damaged Buildings in Crisis Areas
}

\author{
S. Klonus, D. Tomowski, Manfred Ehlers, Member, IEEE, Peter Reinartz, Member, IEEE, and Ulrich Michel
}

\begin{abstract}
This paper describes the results of a new combined method that consists of a cooperative approach of several different algorithms for automated change detection. These methods are based on isotropic frequency filtering, spectral and texture analysis, and segmentation. For the frequency analysis, different band pass filters are applied to identify the relevant frequency information for change detection. After transforming the multitemporal images using a fast Fourier transform and applying the most suitable band pass filter to extract changed structures, we apply an edge detection algorithm in the spatial domain. For the texture analysis, we calculate the parameters energy and homogeneity for the multitemporal datasets. Then a principal component analysis is applied to the new multispectral texture images and subtracted to get the texture change information. This method can be combined with spectral information and prior segmentation of the image data as well as with morphological operations for a final binary change result. A rule-based combination of the change algorithms is applied to calculate the probability of change for a particular location. This Combined Edge Segment Texture (CEST) method was tested with high-resolution remote-sensing images of the crisis area in Darfur (Sudan). Our results were compared with several standard algorithms for automated change detection, such as image difference, image ratio, principal component analysis, multivariate alteration detection (MAD) and post classification change detection. CEST showed superior accuracy compared to standard methods.
\end{abstract}

Index Terms-Change detection, disaster, edge detection, segmentation.

\section{INTRODUCTION}

$\mathbf{F}$ OR change detection from remotely sensed images many methods have been proposed and developed. An overview and comparison of different change detection methods can be found in [1]-[4] or [5]. Generally, change detection methods can be divided into three categories [4]: (i) Image enhancement-

Manuscript received October 31, 2011; revised February 10, 2012, and May 16, 2012; accepted June 10, 2012. Date of current version July 20, 2012.

S. Klonus is with the Institute of Geoinformatics and Remote Sensing, University of Osnabrueck, Osnabrueck, Germany (corresponding author, e-mail: sklonus@igf.uos.de).

D. Tomowski was with the Institute of Geoinformatics and Remote Sensing, University of Osnabrueck, Osnabrueck, Germany. He is now with the Technical University Clausthal, Clausthal-Zellerfeld, Germany (e-mail: daniel.tomowski@tu-clausthal.de).

M. Ehlers is with the Institute of Geoinformatics and Remote Sensing, University of Osnabrueck, Osnabrueck, Germany (e-mail: mehlers@igf.uos.de).

P. Reinartz is with the German Aerospace Center (DLR), Remote Sensing Technology Institute, Department Photogrammetry and Image Analysis, Oberpfaffenhofen, Germany (e-mail: peter.reinartz@dlr.de).

$\mathrm{U}$. Michel is with the University of Education, Heidelberg, Germany.

Color versions of one or more of the figures in this paper are available online at http://ieeexplore.ieee.org.

Digital Object Identifier 10.1109/JSTARS.2012.2205559 methods, (ii) multitemporal analysis, and (iii) post classification comparison. Other approaches combine several methods or consist of novel methodologies (an overview can be found in [5]).

Image enhancement methods are based on unclassified image data which combine the data mathematically to enhance the image quality [6]. Examples of these are image difference, image ratio, or principal component and regression analysis. Multitemporal analysis methods are based on an isochronic analysis of multitemporal image data [1]. This means that $\mathrm{n}$ bands of an image taken on date T1 and $\mathrm{n}$ bands of an image of the same area taken on date $\mathrm{T} 2$ are merged to form a multitemporal image with $2 \mathrm{n}$ bands. This merged image is then used to extract the changed areas [7]. Post classification change analysis is based on a comparison of two independently generated classification results for at least two dates T1 and T2. This method also provides a change analysis; i.e., to determine the kind of change. It is, however, very sensitive to the achieved classification accuracy.

The large number of publications that deal with automated or semi-automated change detection prove that this field is an important research topic [8], for example, combine an image differencing approach with vegetation indices [5], merge image differencing with a principal component analysis [9], use neural networks, whereas [10] and [11] involve fuzzy-set theory for change detection. Other approaches are based on object-based image analysis (see, for example [6] or [12]). In summary, a wide range of different methods have been developed. According to [13], these methods have a different grade of flexibility, robustness, practicability, and significance. Most authors, however, agree that there exist no single best algorithm for change detection. Therefore, new methods are still being developed or adapted especially for the detection of damaged buildings and infrastructure in conflict or crisis areas. This paper is no exception to this, as it describes the development of, and the results for, a set of new change detection algorithms. They were tested with very high resolution (VHR) satellite images of the Darfur conflict area in Sudan. Multitemporal images of the affected regions were recorded by Quickbird-2 and are displayed on a web site that is hosted by Amnesty International clearly showing the destruction for several villages (http://www.eyesondarfur.org/villages.html). With the permission of the satellite company Digital Globe, we were able to use these preprocessed georeferenced Quickbird data that were acquired before and after an attack for our change analysis (see Section IV).

A fast detection and visualization of change in areas of crisis or catastrophes are important requirements for planning and coordination of help. However, a 'best algorithm' for the automated detection of changes for all applications has yet to be 
developed if this is at all possible [13]. Therefore, the objective of our research was to develop a reliable and accurate automated algorithm to detect changes on man-made objects. This algorithm should be used in catastrophic events or humanitarian crises to show the impact of this particular event.

\section{Standard Change Detection Methods}

For a comprehensive assessment of the quality of any new method it is essential to compare it to the performance of standard change detection techniques. The proposed method is an automatic approach; therefore we used for this comparison semi automatic methods. Other, more specific methods use often manual input or additional information such as GIS data or different spectral bands. Software packages as Trimble's eCognition or Feature Analyst from Envi require too much manual input. With this a comparison will be inadequate. Therefore, we selected those that are available in most proprietary image processing systems. These methods are: 1) Image difference; 2) Image ratio; 3) PCA; 4) Multivariate alteration detection (MAD); and 5) post classification analysis.

Image difference is an easily understandable and implementable method [2]. It is based on calculating the per-pixel gray value differences. For every pair of gray values at the same location at dates $\mathrm{T} 1$ and $\mathrm{T} 2$ the difference is calculated. If the resulting values are unchanged or do not exceed a pre-determined threshold no change has occurred. The degree of change is determined by the gray value differences. The image ratio method is very similar to image differencing. For every pair of gray values at the same location at dates $\mathrm{T} 1$ and T2 the per-pixel ratio of the two values is calculated. Both methods vary through different spectral band combinations, the choice of thresholds, or different available spectral resolutions. Especially, the choice of a suitable threshold level is a critical factor, because of a time consuming manual interpretation and the integration of a priori knowledge in the analysis process [14].

The principal component (PC) transform is a statistical method to calculate a new synthetic (uncorrelated) data space. With this approach, it is possible to strengthen wavelength dependent material specific differences. Detailed explanations of this method can be found, for example, in [15] or [16]. Principal component analysis (PCA) can be used in different ways for change detection [17]. In this study, we employ a selective bitemporal PCA (for more information see [18]). Two bitemporal spectral bands of the same location are analyzed in a two dimensional feature space. As a result, all gray values are located in relation to the two principal components. Usually, the unchanged pixels show a high correlation with the first principal component in contrast to the changed pixel. As a consequence, the first principal component contains the 'unchange' information and the second component the 'change' information [3].

Post classification analysis is based on a comparison of two independent classification results for at least two dates $\mathrm{T} 1$ and T2. This method allows the determination of the kind of change from one class to another. For example, each input data set of T1 and $\mathrm{T} 2$ can be classified with the unsupervised isodata algorithm [14] using 20 classes.

The multivariate alteration detection (MAD) [19] uses canonical correlation analysis to find relationships between two datasets. The canonical analysis provides two sets of linear combinations of the original data. The first two linear combinations (canonical variates) have the largest correlation (first canonical correlation). The second canonical variates have the second largest correlation and are orthogonal to the first canonical variates. Basis for the change detection approach is the difference between these pairs of variates. The MAD transformation is defined as

$$
\left[\begin{array}{c}
X \\
Y
\end{array}\right] \rightarrow\left[\begin{array}{c}
a_{p}^{T} X-b_{p}^{T} Y \\
\vdots \\
a_{l}^{T} X-b_{l}^{T} Y
\end{array}\right]
$$

\section{Combined Edge Segment TeXture (CEST) Analysis FOR CHANGE DETECTION}

Because simple methods such as image difference or image ratio (see results in Section $\mathrm{V}$ ) failed to detect reliably changes of buildings in the study images, we had to develop a different procedure for automated change detection. This procedure is based on several different principles: frequency based filtering, segmentation, and texture analysis. Four of these methods are based on filtering in the frequency domain after a Fourier transform ([20], [21]), one on segmentation and the others on texture features. The frequency domain is used because it allows the direct identification of relevant features such as edges of buildings. If no features are directly visible (such as partial destruction with still standing outside walls), texture parameters are used for debris identification. A segmentation algorithm is used to extract size and shape of buildings. These methods can be combined in a decision tree for accuracy improvement. The combination of these processing steps is called Combined Edge Segment Texture (CEST) analysis.

\section{A. Fourier Transform Based Algorithms}

The Fourier transform is defined for s single-band or panchromatic images [22]. Based on a frequency analysis in the spectral domain, isotropic band pass filters can be designed to highlight selected frequencies and - as such-structures in the images. In a first step very narrow band pass filters are created. All band pass filters are analyzed visually in the spatial domain. In doing this it is possible to discern between high frequency noise and frequency bands that contain information. Based on this analysis different frequencies are combined to an information enhancing band pass filter. Different single and multiple frequency band pass filters can be designed covering the whole range of available frequencies. The design of band pass filters in the frequency domain is based on size and resolution of the images, and the estimated size of buildings and man-made structures where changes are to be detected. The orientation of the buildings has no influence due to the use of isotropic band pass filters. The filtered images are then transformed back into the 
spatial domain for further analysis. Higher frequencies visualize the position of building, the highest frequencies, however, contain mostly noise and are not useful for object identification and extraction. Lower frequencies contain mostly general image background which is not used for further analysis. After several tests, an optimum band pass filter is created which includes the most appropriate information for building extraction. With an image size of $1024 \times 1024$ pixels, this adaptive band pass filter ranges from a spatial frequency of 100 to 378 . Different tests conclude that this filter can be adapted also to other images. For an image with a pixel size of $2048 \times 2048$ this band pass filter would have a spatial frequency from 200 to 756, respectively [23]. To avoid the Gibbs problem, the filter was smoothed with a Hanning window [20], [24].

After transforming $\mathrm{T} 1$ and $\mathrm{T} 2$ via $\mathrm{FFT}$ and the adaptive band pass filtering four different methods are analyzed to extract the changed structures: 1) subtraction in the frequency domain, 2) correlation in the frequency domain, 3) correlation in the spatial domain, and 4) edge detection in the spatial domain. Of these methods, the best results are obtained using the edge detection algorithm [23]. Consequently, we incorporated this method as a standard into the CEST analysis. The Edge Detection in the spatial domain consists of the following steps: The band pass filtered images T1 and T2 are first transformed into the spatial domain by an inverse FFT. Thereafter, an edge detection operator is applied to both images. The best results are obtained by the Canny edge detector [25]. To avoid small registration errors morphological closing is used before subtracting the scenes from each other; afterwards a morphological opening is applied.

\section{B. Methods Based on Texture Parameters}

Frequency based filtering is particularly suited to detect changes in edge structures. If edges remain intact, however, textural features may be used for change analysis. For the calculation of texture parameters, we make use of the Haralick features [26]. This is based on the gray-level co-occurrence matrix (GLCM) [26]. The idea is that buildings can have higher texture values than areas without buildings (see, for example, [27]-[29]). This is especially true if the surrounding environment is very homogeneous and the buildings are very small or destroyed (with surrounding debris). A GLC matrix describes the likelihood of the change of the gray value $i$ to gray value $j$ of two neighboring pixels [30]. In the calculation of a GLCM, the frequency of all possible gray values combinations at two neighbor locations is counted for a defined number of directions (e.g., $0^{\circ}, 45^{\circ}, 90^{\circ}$ or $135^{\circ}$ ). The calculation of the average of these matrices for every element yields a direction-independent symmetric matrix.

Finally, to calculate the likelihood $\mathrm{P}_{\mathrm{i}, \mathrm{j}}$ of a gray value change, every value in this matrix is divided by the maximum number of all possible gray value changes:

$$
P_{i, j}=\frac{V_{i, j}}{\sum_{i, j=0}^{N-1} V_{i, j}}
$$

where $\mathrm{V}$ denotes the value in the symmetric GLCM, $i$ and $j$ are the row and column index and $\mathrm{N}$ is the number of rows and columns.
The calculation of the GLCM for images of high radiometric resolution is very time consuming. To reduce this effect, [26] suggest different texture features (the now well-known 'Haralick' features) which represent the characteristic of a matrix in one comprehensive value. To achieve this result, the features are calculated using a window technique [31]. Initial tests with several Haralick features showed that 'energy' and 'inverse distance moment' (IDM, also known as 'homogeneity') produced the best results for man-made objects (for more information see [18], [30]). Consequently, these features were used for the CEST method.

The GLCM ( 8 bit) for every image is calculated after an initial histogram matching of the multitemporal images. Based on the GLCM, the texture features IDM and energy are computed with differently sized windows (ranging from $3 \times 3$ to $17 \times 17$ pixels). Best results are obtained with a $13 \times 13$ window. The calculated texture images at dates $\mathrm{T} 1$ and $\mathrm{T} 2$ are the input for a selective bitemporal principal component analysis (PCA). In comparison to other change detection methods like image difference, image ratio and regression analysis the PCA shows the best results for the visualization of settlement change in arid regions [18].

\section{Change Detection Based on Segmentation}

Object or segment based image analysis has gained a lot of interest in the remote sensing community (see, for example, [32]). Segmenting an image seems to be an excellent pre-analysis tool, especially for images of very high resolution. Consequently, we developed a segmentation procedure to be used for change detection. The segmentation method that we developed for our study is based on the Euclidean distance. The gray value range is calculated and divided by a constant. The result is used as a threshold. For each pixel, the Euclidean distance to each neighboring pixel is calculated. If the Euclidean distance of the gray values is below the threshold, they belong to the same segment. After an independent segmentation of the images at dates $\mathrm{T} 1$ and $\mathrm{T} 2$, the segments of $\mathrm{T} 1$ are selected and used also for the T2 image. For each segment, the T1-T2 correlation coefficient is calculated. The result is assigned to each pixel in the segment. A new layer with the result of this segmentation is then created. Segments with a high correlation represent no changes. Segments with a low correlation represent changes.

However, if only one image is segmented, objects occurring only in one image are not recognized as a segment in the other image and are therefore assigned to a larger segment in this image. After correlation this segment has probably a low value. However, the change is not related to the whole segment, but only to a part of it. To solve this problem, this procedure is repeated for the other image. For this step, the segments of T2 are selected and superimposed on the T1 image. Again, the correlation coefficient - this time between $\mathrm{T} 2$ and $\mathrm{T} 1$ - is calculated for all pixels in each segment. The segmentation is done independently in both images. The results are combined using different conditional statements. If, for example, the T1 image contains several buildings in a specific area which are not present in the T2 image, there exists a high probability that this area forms a large segment in T2 but is split into several small segments in T1. This would create incorrect change indications. As 


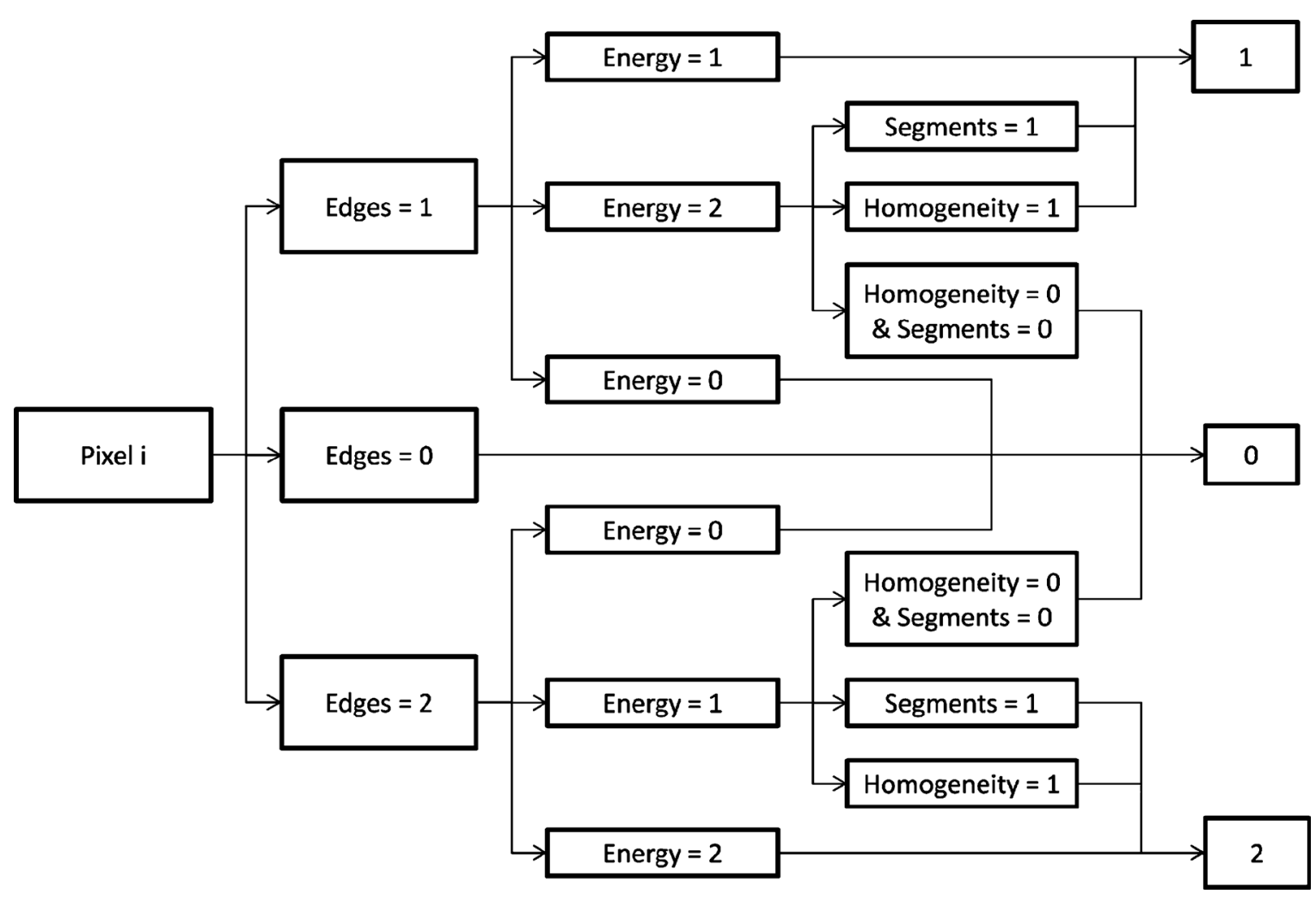

Fig. 1. Decision tree for the combination of change detection methods (CEST): Edges = result of the edge detection based on filtering in the Fourier domain Segments $=$ result of the change detection using segmentation. Homogeneity and Energy $=$ results of the texture features. Numbers are related to the following classes: Class $0=$ unchanged buildings, class $1=$ changed/destroyed buildings, class $2=$ new buildings.

a final step, thresholds are used to extract the change segments [22]. An implementation of the multiresolution approach [33] was also tested, but the settings were not transferable to other areas. Additionally, the algorithm we used could be applied with the same setting to other areas.

\section{Combined Change Detection: The CEST Method}

Finally, all three methods are combined in a decision-tree approach (Fig. 1). The basis for the classification is the result of the change detection algorithm using edge detection based on frequency filtering. If the edge parameter shows 'no change', the pixel in the image is classified as 'no change'. If the edge parameter shows 'new building', the pixel is classified as new, if the texture feature 'energy' is an agreement. If energy shows 'change' and one of the features 'homogeneity' or 'segmentation' shows 'change', the result is 'new'. Otherwise, it is classified as unchanged. If the edge parameter shows 'change', it is classified as 'change' if the texture feature 'energy' coincides. If energy shows 'no change', the pixel will be classified as 'no change'. If energy shows 'new' but the segment and homogeneity parameters show 'change', the pixel is assigned to 'change'. Otherwise it is classified as unchanged. The CEST procedure was tested against the standard change detection methods described in 3.1.

\section{E. Automatically Created Change Maps}

The produced change images are to a large degree abstract and hard to interpret. This holds particularly true for people not related to remote sensing such as members of official organizations or rescue forces. For planning after a crisis or a catastrophe, the interpretation of change images should be as easy as possible. An algorithm was developed to automatically produce a map which can be easily interpreted. The first step is to generalize the change image. Inside a $20 \times 20$ pixels window, the amount of change is determined using the information in the change image. The change percentage of this area is calculated and then ranked into a number of distinctive general classes. If less than $15 \%$ of the area has changed, all pixels are classified as unchanged. Change above $80 \%$ marks extensive change and change between $15 \%$ and $80 \%$ marks low to moderate change. Areas of new buildings with a surface cover of at least $15 \%$ are showed as 'new areas'.

\section{STUDY AREA}

CEST detection and change map generation methods are now applied to the selected study sites in Darfur, Sudan. They represent areas which experienced dramatic changes during the Darfur conflict. This conflict is a dispute between different ethnic groups and the Sudanese government. Although the conflict in Sudan has recently been less intense than it has been in the past, all sides to the conflict continue to commit violations of international humanitarian law, such as attacks on civilians and on humanitarian convoys. It is estimated that more than 300.000 people have already died in this conflict and more than two million people have been displaced (http://www.eyesondarfur.org/villages.html). 


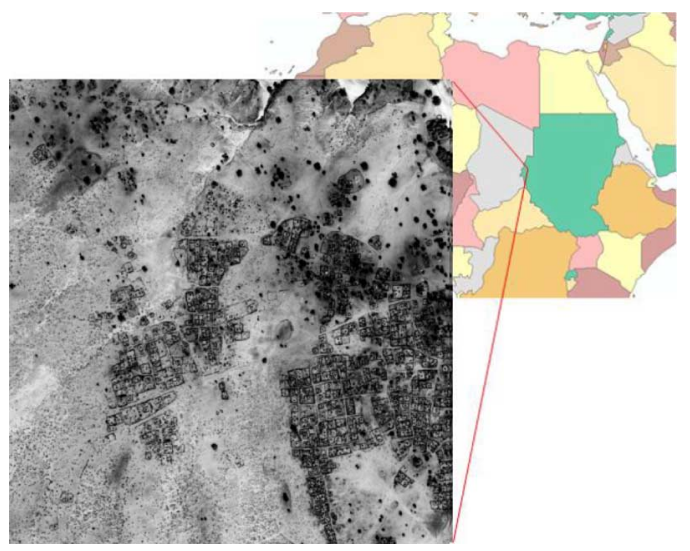

Fig. 2. Geographic location of study site.

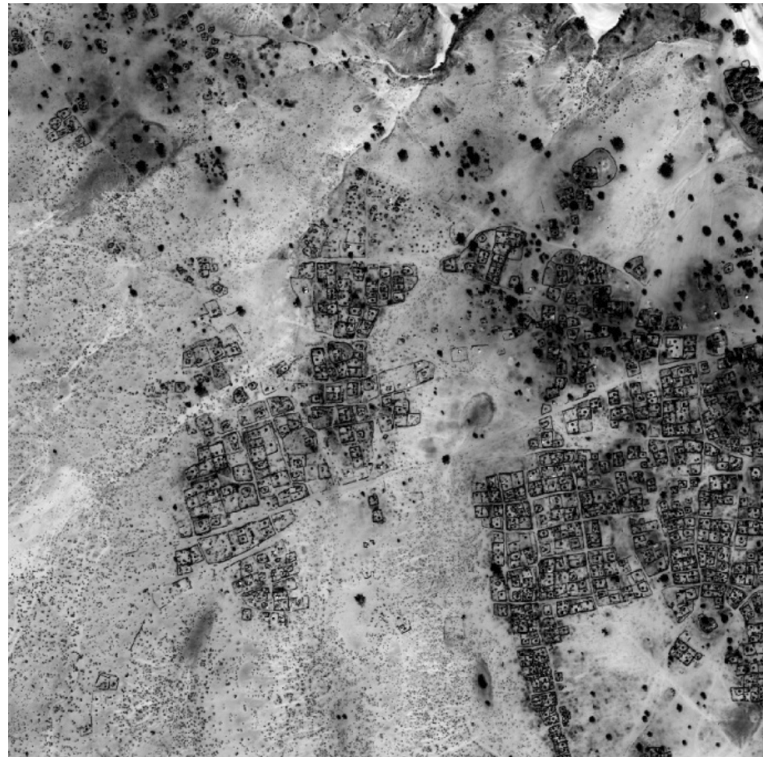

Fig. 3. Panchromatic Quickbird-2 image recorded on March 2, 2006 of the town Abu Suruj ( $2048 \times 2048$ pixels). Images are provided by Amnesty International, courtesy of Digital Globe.

The test area is located in South Darfur (Fig. 2) and shows part of the town Abu Suruj in West Darfur. The images were taken by Quickbird-2 on March 2, 2006; a subset of the scene is presented in Fig. 3, before the attack (T1) and February 28, 2008 (Fig. 4) after the attack. These images were also provided by Amnesty International, courtesy of Digital Globe. Because of new settlement areas, this study site is very complex. It contains changes due to destruction and - at the same time - changes due to construction. A change detection procedure should be capable of depicting both types of change. This is demonstrated in Fig. 5 which shows the manually digitized man-made structures. Black denotes no changes (background), white stands for new buildings (construction) and gray for changed buildings (destruction). Most changed buildings are located in the east of the image with the new buildings in the west. Figs. 6 and 7 show subsets of Figs. 3 and 4. The left images (Figs. 6(a) and 7(a)) present the panchromatic T1 image recorded on March 2, 2006 and the right images (Figs. 6(b) and 7(b)) the panchromatic T2

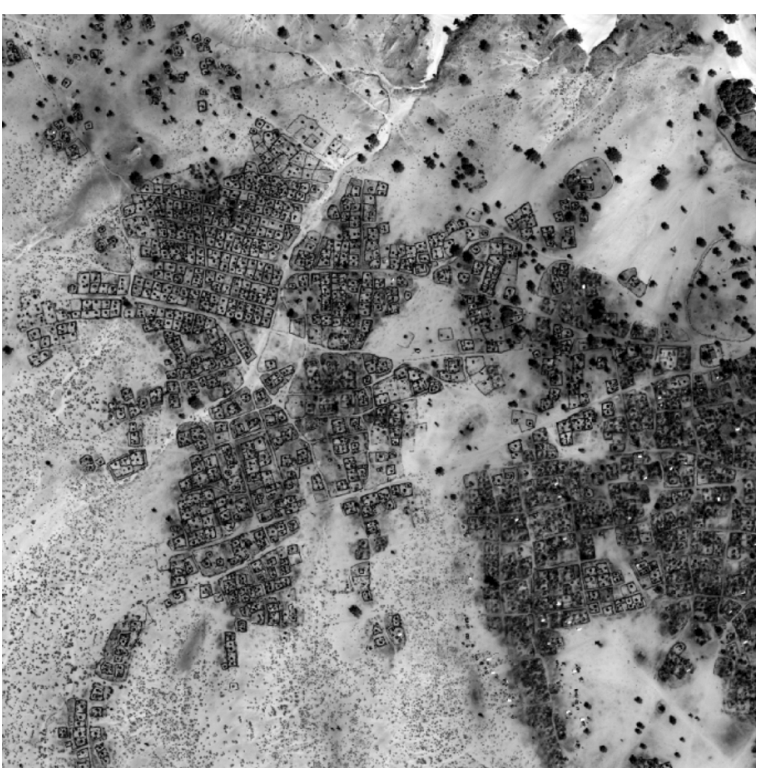

Fig. 4. Panchromatic Quickbird-2 image recorded on February 28, 2008 of the town Abu Suruj ( $2048 \times 2048$ pixels). Images are provided by Amnesty International, courtesy of Digital Globe.

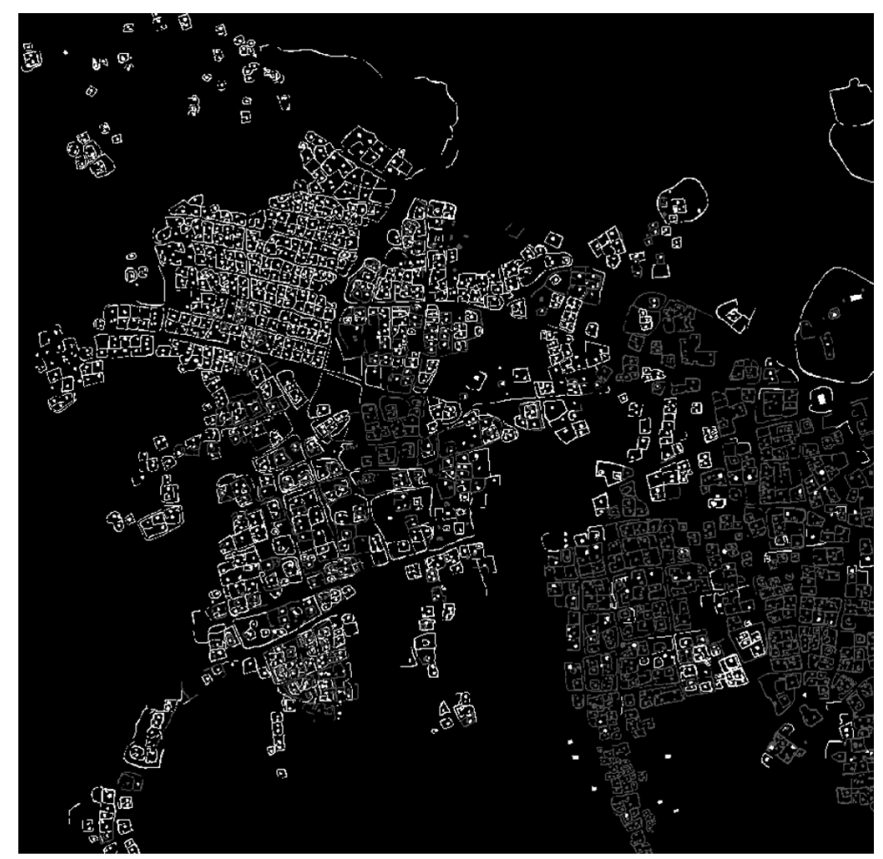

Fig. 5. Manually digitized reference image of the town Abu Suruj. Black denotes no changes (background), white stands for new buildings (construction) and gray for changed buildings (destruction).

image recorded on February 28, 2008. Fig. 6 displays buildings which are destroyed in $\mathrm{T} 2$ but did exist in T1. The two existing buildings in Fig. 7(a) were destroyed during 2007 but new buildings are constructed at the same place and are visible in T2.

A visual comparison and overlay of the existing man-made structures shows a high correspondence for both images, so that a new co-registration was not necessary and the problem of possible pseudo change was negligible. These images were used for the following analysis in the next section. They were 


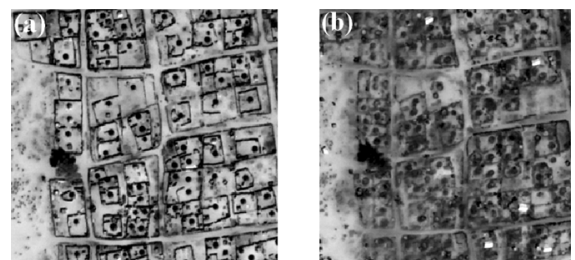

Fig. 6. Subset of the panchromatic Quickbird-2 images recorded on March 2, 2006 (a) and on February 28, 2008 (b) of the town Abu Suruj. The image (a) shows intact buildings and the image (b) destroyed buildings.
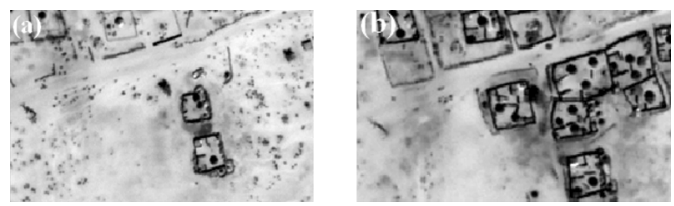

Fig. 7. Subset of the panchromatic Quickbird-2 images recorded on March 2, 2006 (a) and on February 28, 2008 (b) of the town Abu Suruj. The image (a) shows two intact buildings which are destroyed in image (b) but also with new buildings that were constructed on the same location.

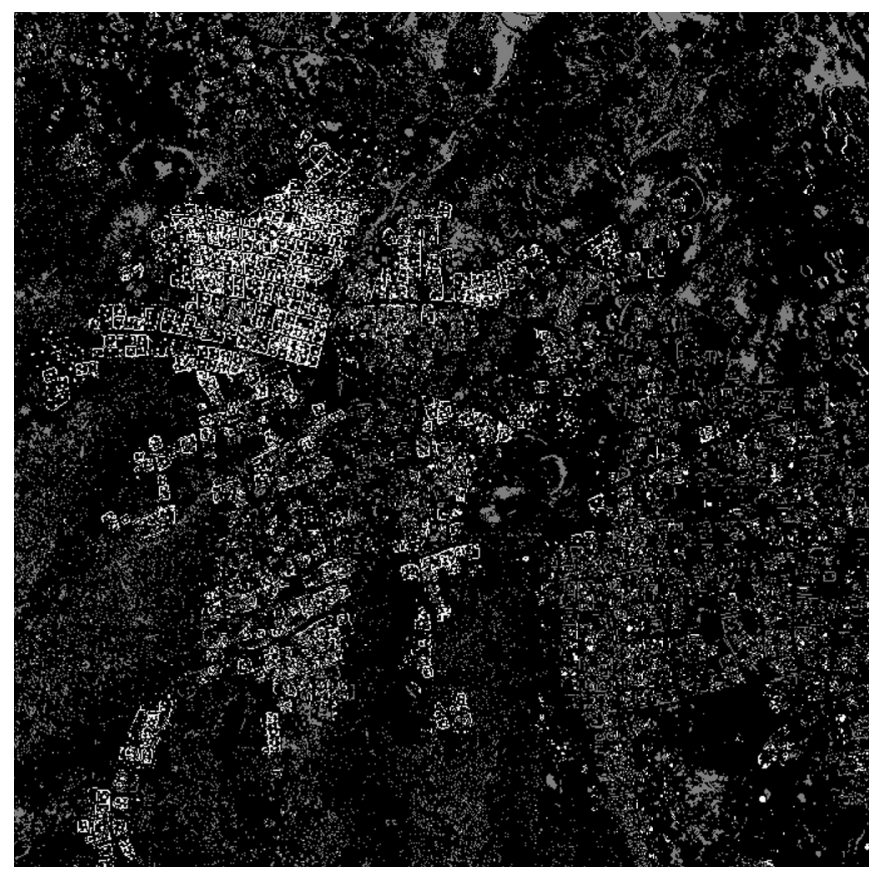

Fig. 8. Result of change detection using image difference, black denotes no changes (background), white stands for new buildings (construction) and gray for changed buildings (destruction).

preprocessed using a histogram matching procedure. An atmospheric correction is not applied, due to missing ground truth data, sparse vegetation and only one image band.

\section{RESUlts AND ACCURACY ASSESSMENT AND COMPARISON}

In the following section, the classification results of the standard methods (Section II), the new CEST-method (Section III) and the achieved accuracies are presented. For the accuracy assessment three classes were selected:

Class $0=$ unchanged buildings

Class $1=$ changed or destroyed buildings

Class $2=$ new buildings.
The reference is a manual digitization of buildings through an independent photointerpreter (see Fig. 5). Accuracy assessment for classes 1 and 2 is based on 404 randomly chosen digitized objects. Only for class 0 all 404 objects were used. If most of the pixels inside an object are the pixels of the correct class, the whole object was considered as correctly detected. Producers' accuracy, users' accuracy and the kappa coefficient are calculated for all scenarios.

\section{A. Image Difference}

By using different thresholds it is possible to detect the three different classes (positive change, negative change and no change). It can be seen, however, that large areas of pseudo change are detected (Fig. 8). Due to brightness changes of the sediment, change is especially detected in the north of the image. Most of the new buildings which appear in the T2 image are detected. Buildings which are unchanged are often identified as destroyed or changed buildings. These results are also confirmed by the accuracy assessment (see Figs. 14 and 15).

\section{B. Image Ratio}

For image ratio, it is difficult to find a threshold between new and changed/destroyed buildings. Therefore most of the buildings are detected as new buildings (Fig. 9). As with image difference, buildings which are unchanged are often detected as destroyed or changed. This leads to the extremely low producers accuracy of $8.2 \%$ for class 1 (changed or destroyed buildings). The amount of detected pseudo change is relatively low in comparison to image difference.

\section{C. $P C A$}

The image processed with the PCA change detection procedure shows a lot of pseudo change, especially in the south and west of the image. Similar to the image ratio, most of the buildings are detected as new buildings (Fig. 10). Also, nearly $45 \%$ of the unchanged buildings are classified as changed/destroyed. $30 \%$ of the destroyed or changed buildings, on the other hand, are classified as unchanged.

\section{Multivariate Alteration Detection (MAD)}

The MAD results are comparable with the results from Image differencing (Fig. 11). There is still a lot of pseudo change appearing in the image; most of the change in the environment is detected. $45 \%$ of the buildings which remain intact are not detected.

\section{E. Post Classification Analysis}

For the post classification analysis we used the isodata algorithm [14], because no appropriate training areas were available. For the analysis, three following classes are extracted: new buildings, changed buildings and background or unchanged buildings, respectively. The post classification result (Fig. 12) produces the lowest accuracies (see Figs. 14 and 15). Nevertheless, the producer accuracy show $90 \%$ of the changed buildings can be detected but the user accuracy shows that $50 \%$ of the destroyed buildings are classified as unchanged. Nearly $80 \%$ of 


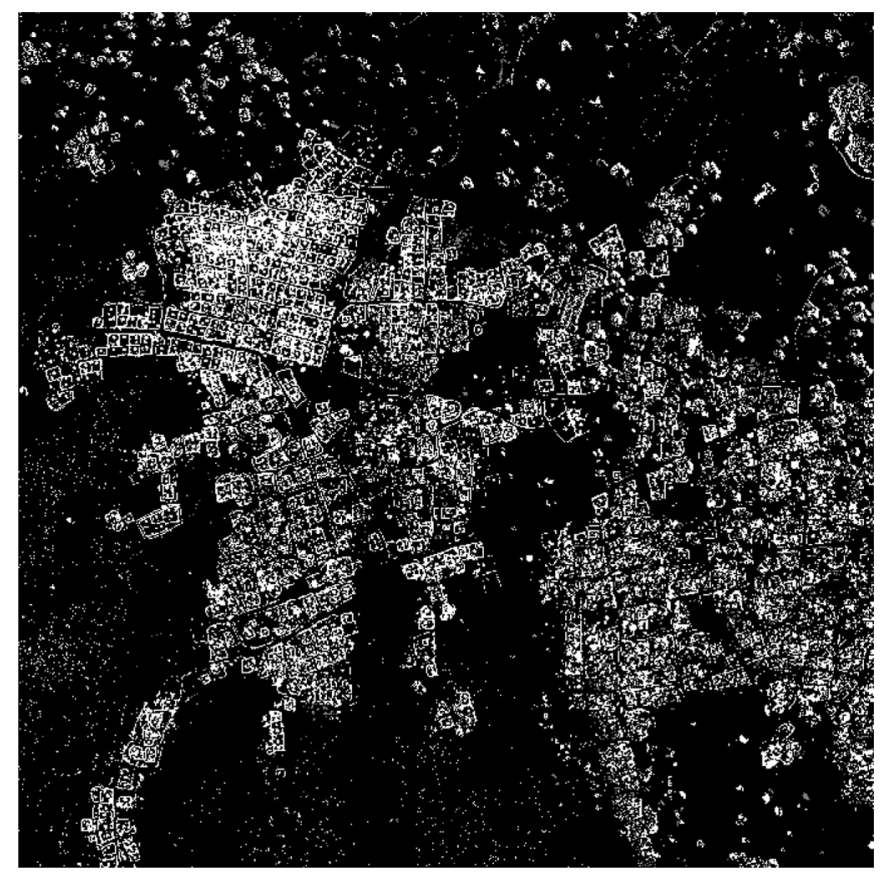

Fig. 9. Result of change detection using image ratio, black denotes no changes (background), white stands for new buildings (construction) and gray for changed buildings (destruction).

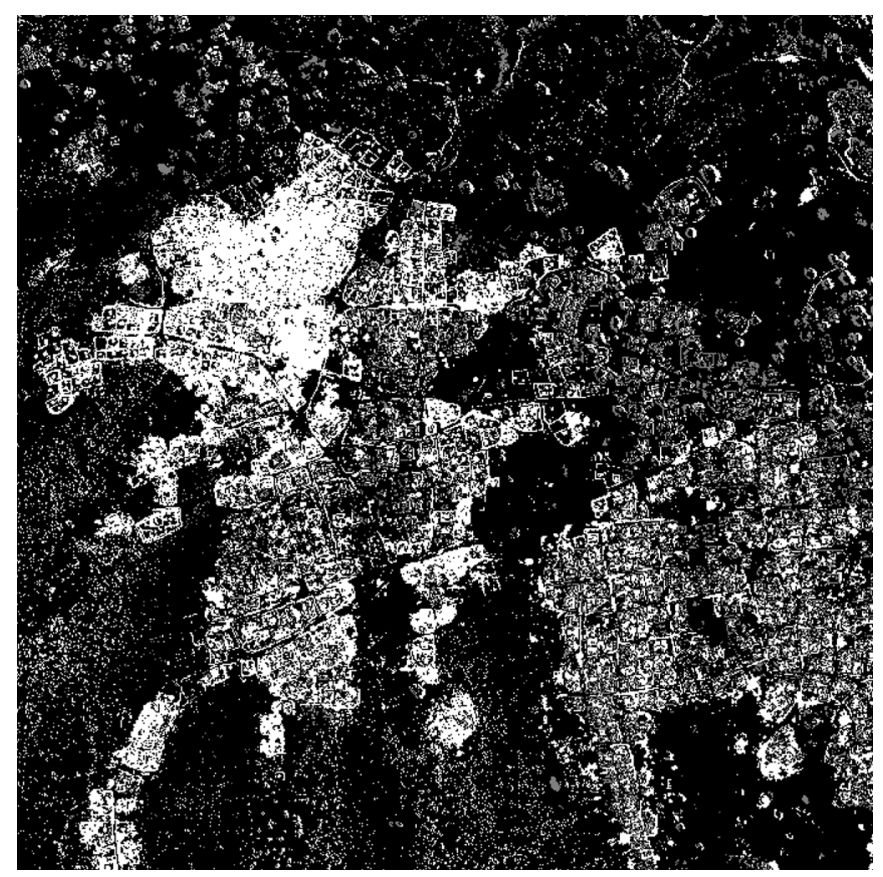

Fig. 10. Result of change detection using PCA, black denotes no changes (background), white stands for new buildings (construction) and gray for changed buildings (destruction).

the buildings which are new in image T2 are classified as unchanged. Again, pseudo change poses a big problem.

\section{F. CEST Method}

As a first step, we assess the quality of the single methods that make up CEST. A quantitative analysis, however, was only performed for the combined CEST method. Because the Abu Suruj area contains also new construction, the algorithm identifies

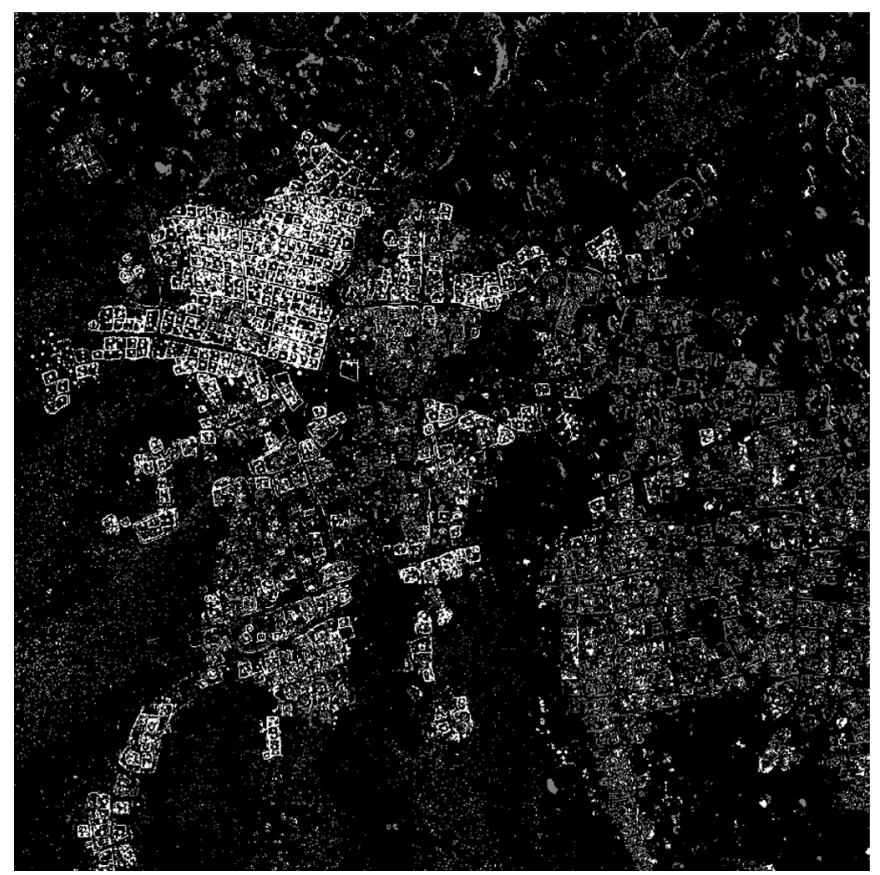

Fig. 11. Result of change detection using MAD, black denotes no changes (background), white stands for new buildings (construction) and gray for changed buildings (destruction).

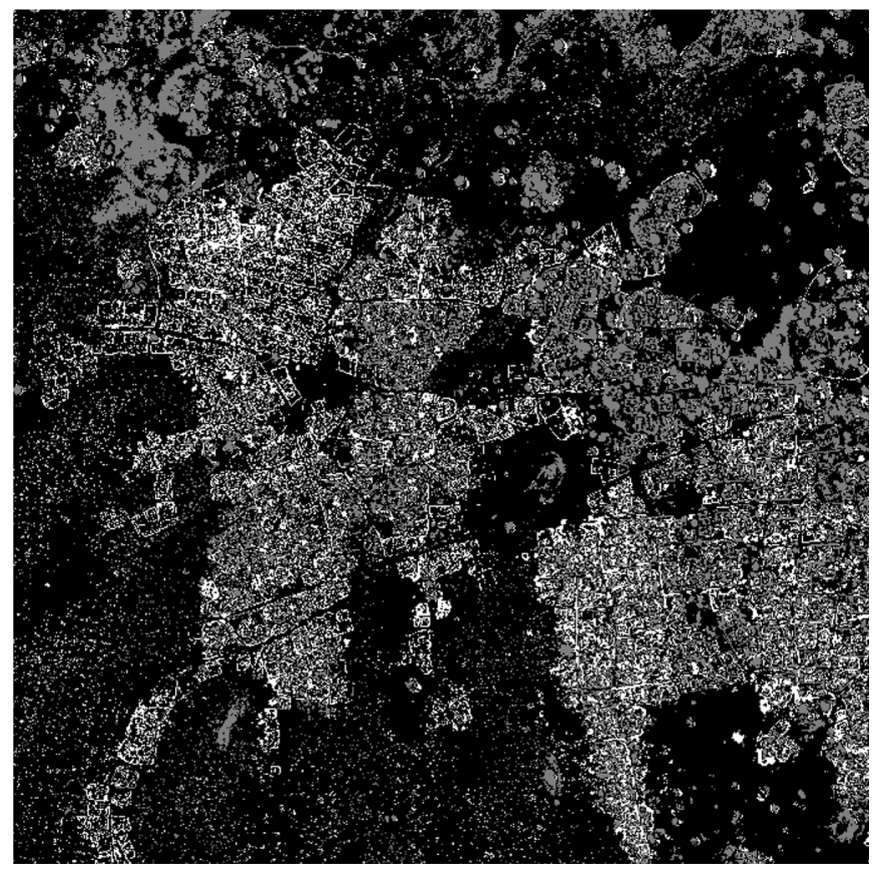

Fig. 12. Result of change detection using post classification, black denotes no changes (background), white stands for new buildings (construction) and gray for changed buildings (destruction).

three classes. With the change detection based on frequency domain filtering and subsequent edge detection, it proved possible to identify unchanged areas, new settlements and destroyed settlements, even single huts and changed walls.

For the PCA method using the Haralick 'energy' feature, also three classes can be extracted. This means that the direction of changes can be depicted by this method (positive and negative change). To find these classes, Otsu's thresholding is used [34]. 


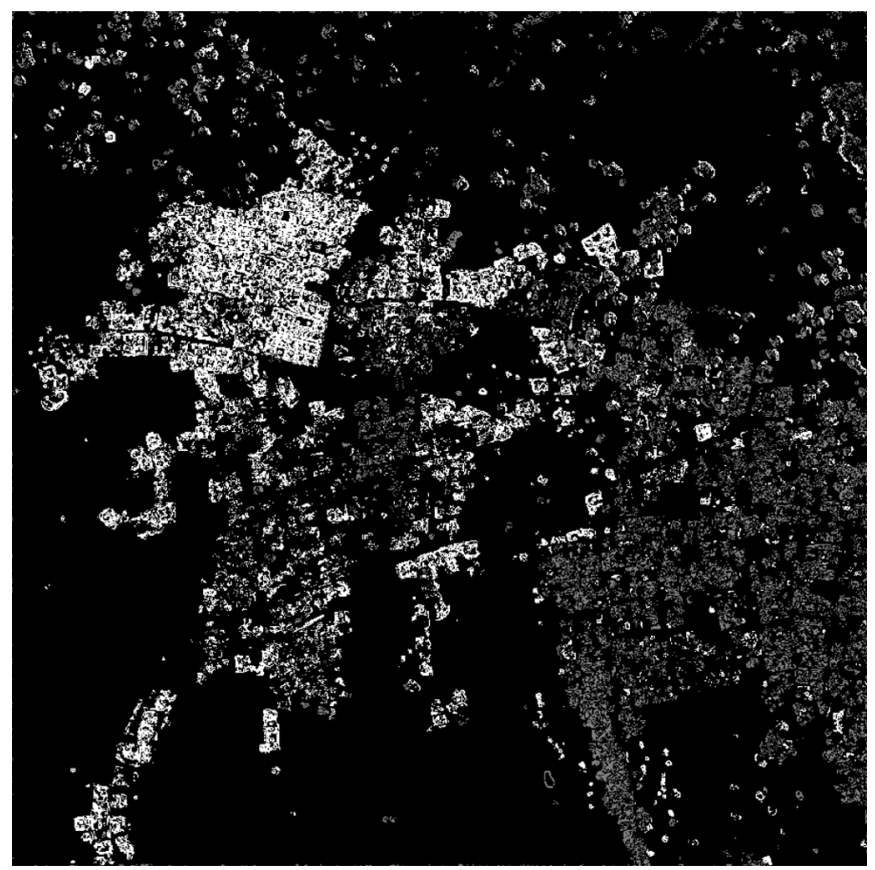

Fig. 13. Result of change detection using the CEST method. This result combines the advantages of all methods and generates the most accurate change image. Three change classes can be identified: black denotes no changes (background), white stands for new buildings and gray for changed/destroyed buildings.

The location of the buildings is not very accurate in both images; the walls are wider than in reality and the area inside the walls is often detected as change. This effect can be an indicator for different viewing angles or illumination conditions in both images.

The last of our newly developed methods, the segmentation based change detection, produces better results for this test area than the edge detection or the texture procedure. The boundaries are clearly defined and objects can be better identified. Some parts of the vegetation, however, are identified as changed buildings. Additionally, some noise appears.

Finally, these methods are combined in the CEST approach to make use of the advantages of each individual algorithm. The result is shown in Fig. 13. In comparison to the other methods, this image contains far less noise. Also, misclassification of vegetation as changed buildings is significantly less. Similar to the bitemporal PCA for the texture images, the results contain three distinctive classes: black for no changes, white for new buildings and gray for changed/destroyed buildings. In addition, the walls of the buildings are more accurate than for the PCA result. In total, the combination of all three methods generates the most reliable and accurate results for change detection.

\section{G. Quantitative Analysis}

The results of the visual analysis are confirmed by the quantitative accuracy assessment. The accuracies of the CEST-Method are the best in this study. $97 \%$ of the unchanged buildings are correctly detected. Although nearly $35 \%$ of the changed or destroyed buildings are identified as unchanged the CEST result is still acceptable. In comparison to all other

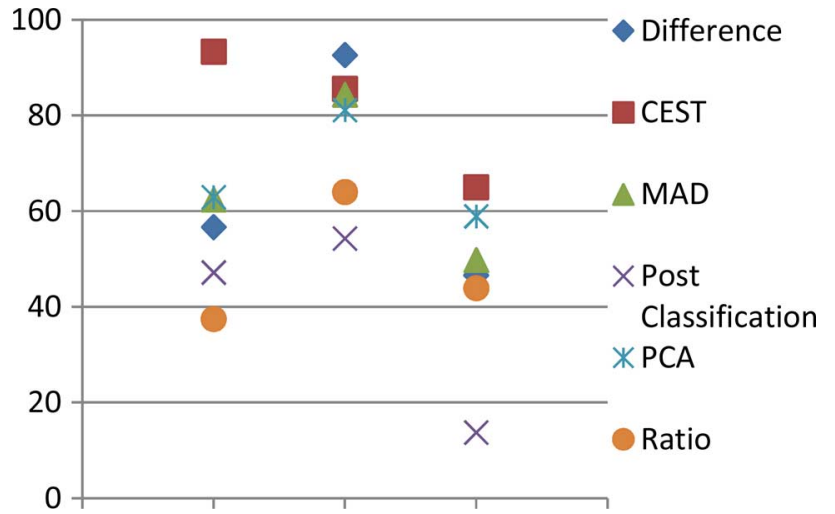

Fig. 14. Users' accuracy for the 3 classes (class $1=$ changed or destroyed buildings, class $2=$ new buildings and class $3=$ unchanged buildings).

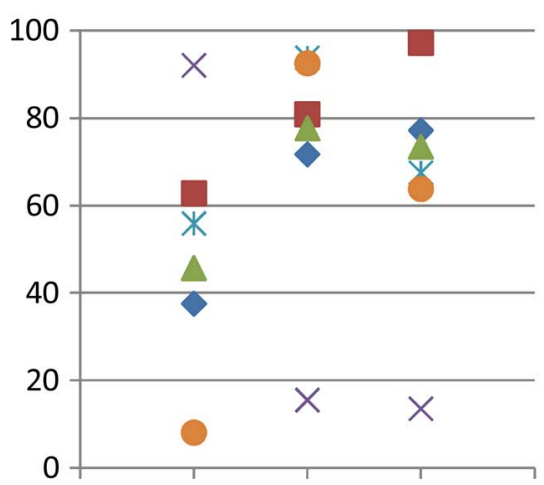

Difference

CEST

$\triangle M A D$

$\times$ Post

Classification

* PCA

Ratio

Fig. 15. Producers' accuracy for the 3 classes (class $1=$ changed or destroyed buildings, class $2=$ new buildings and class $3=$ unchanged buildings).

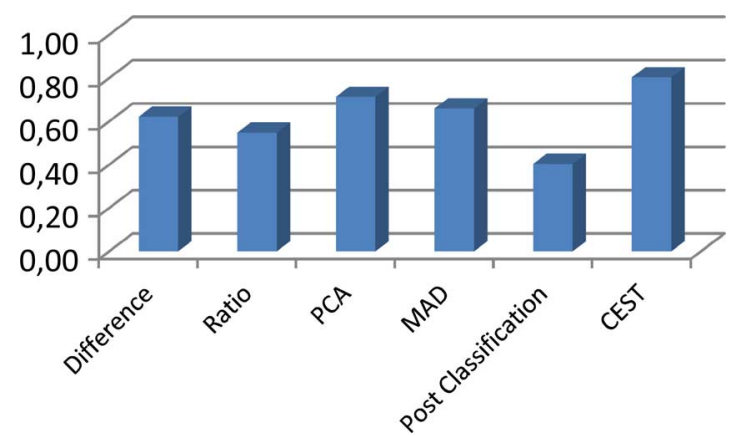

Fig. 16. Overall accuracy for the change detection methods in the Abu Suruj area.

algorithms, however, this combined method shows the highest users and producers accuracies and produces also less pseudo change. Figs. 14 and 15 show the users' and producers' accuracies, respectively.

A comparison of overall accuracy is presented in Fig. 16. As expected, the CEST approach shows the highest accuracy with about $80 \%$. Acceptable values are also associated with Delta cue $(72 \%)$ and PCA $(71 \%)$. The worst results are produced by the post classification approach with $40 \%$. This demonstrates clearly the inferiority of the selected standard methods for the automated change detection in crisis areas.

Looking at Figs. 8-13, it is quite clear, that the CEST approach provides the best result whereas all other images present 
TABLE I

Histogram VALUES OF the Figs. 8-13 In COMPARISON TO THE REFERENCE

\begin{tabular}{|l|rrr|}
\hline & Class 0 & Class 1 & Class 2 \\
\hline Reference & 3817580 & 168469 & 208255 \\
Diff & 3612355 & 388745 & 193204 \\
Ratio & 3624907 & 56039 & 513358 \\
PCA & 3216854 & 193105 & 784345 \\
MAD & 3243048 & 397981 & 553275 \\
Post Classification & 3173223 & 627516 & 393565 \\
CEST & 3859368 & 145124 & 189812 \\
\hline
\end{tabular}

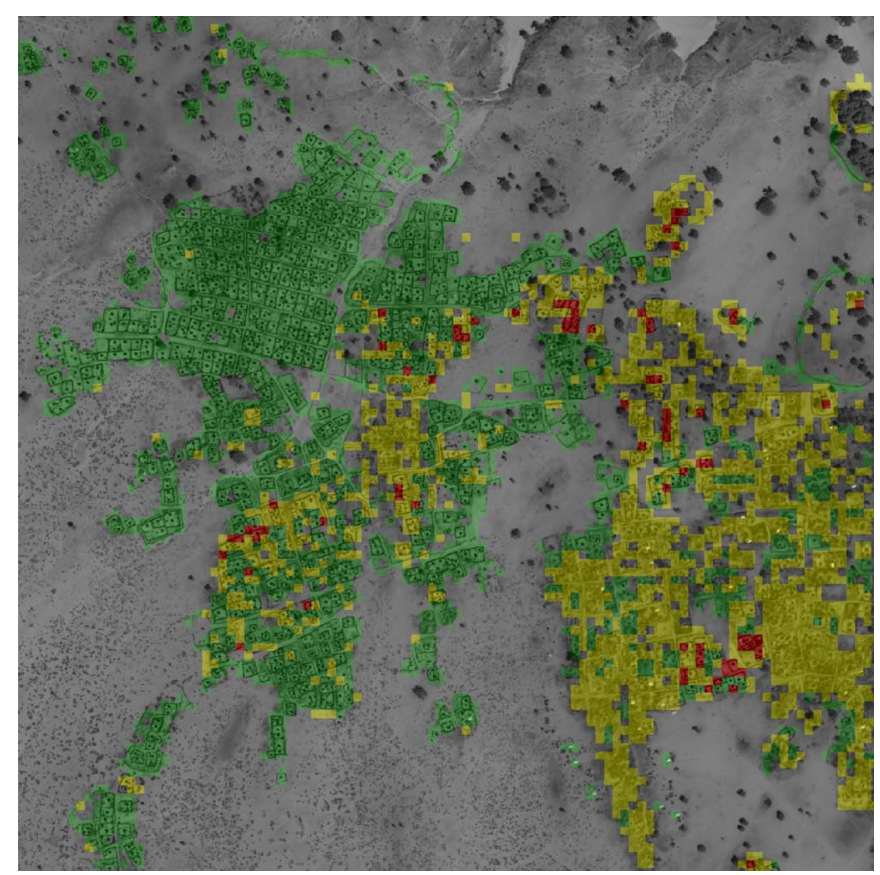

Fig. 17. Generalized change map of Abu Suruj: new buildings (green), low to moderate change (yellow), extensive change (red).

a large amount of noise. This is confirmed by Table I, which shows the number of pixels that are assigned to each class.

Evidently the CEST method has the highest correspondence to the original values.

\section{H. Change Map}

Finally, a damage map can be created (Fig. 17). For this, the original image of $\mathrm{T} 2$ is used as background for automatically created change maps and for the results. Unchanged areas are transparent, low to moderate change areas are shown as yellow overlay, and areas of strong changes as red overlay. New building areas are shown in green. If this technique is applied to areas with catastrophic events, this change map makes it possible to quickly identify the most affected areas or the areas for which high casualties are likely. For the Abu Suruj area, it could be easily depicted that the town has increased, but also that large parts have changed. Buildings were destroyed and new buildings were built on these sites or next to the destroyed buildings.

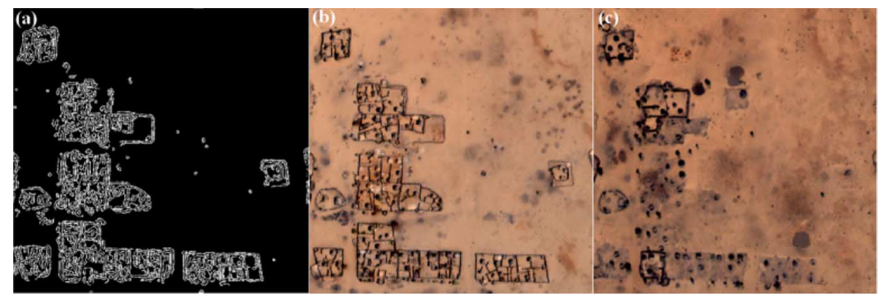

Fig. 18. Subset of the area Shangil: (a) Result of change detection (black: no change, white: change), (b) image from 2005 and (c) image from 2006.

\section{TRANSFERABILITY}

The method is also transferable to other scenes of Darfur. Fig. 18 shows the region around Shangil, a sparsely populated area which is the home of several thousands of displaced civilians. The attacks on this village took place between 2005 and 2006. The images were taken by Quickbird on 10 March 2003 - a subset of the scene is presented in Fig. 18(b) - before the attack and 18 December 2006 (Fig. 18(c)) after the attack. These images were also provided by Amnesty International. It is visible, that the whole village was destroyed, some of the structures were completely wiped out, some were burnt down and are still partly visible. The change detection result is displayed in Fig. 18(a). All destroyed buildings could be detected. It seems that some of the buildings had just darker and wider walls than in the $\mathrm{T} 1$ image. Thorough visual inspection showed that the houses were indeed burnt down and these burnt remains were still visible and just looked like darker and wider walls.

In addition, the CEST method was tested in Munich, Germany (Fig. 19). The center image subset shows the location (parking lot) before the Oktoberfest, the world famous German beer festival. The image at the right shows the festival area with a large number of parked busses. The left image shows the detected changes in white. The CEST method detected all busses as changes to the previously empty parking lot. Due to problems with orthorectification, different morphological operations had to be applied. As a result, the unchanged spaces between the parked busses were also assigned to the class 'change'. It has to be noted that at this point of time, only visual analysis for $\mathrm{Mu}$ nich has been performed. Statistical evaluations have not yet been completed.

\section{CONCLUSION AND FUTURE WORK}

In this paper, a new automated change detection method (CEST) is presented. CEST combines adaptive filtering in the frequency domain with edge detection in the spatial domain, calculation of the texture features 'homogeneity' and 'energy' with a PCA change detection approach and segment based correlation. This combined method is compared to five standard change detection algorithms (image difference, image ratio, PCA, MAD, and post classification analysis). Results are visually and quantitatively analyzed. The accuracy assessment shows that the CEST method is far superior to the standard techniques for change detection. Despite the fact that CEST is more complex than the tested standards methods, CEST can be completely automated and transferred to other areas. The combined method yields an overall accuracy of $80 \%$ and 

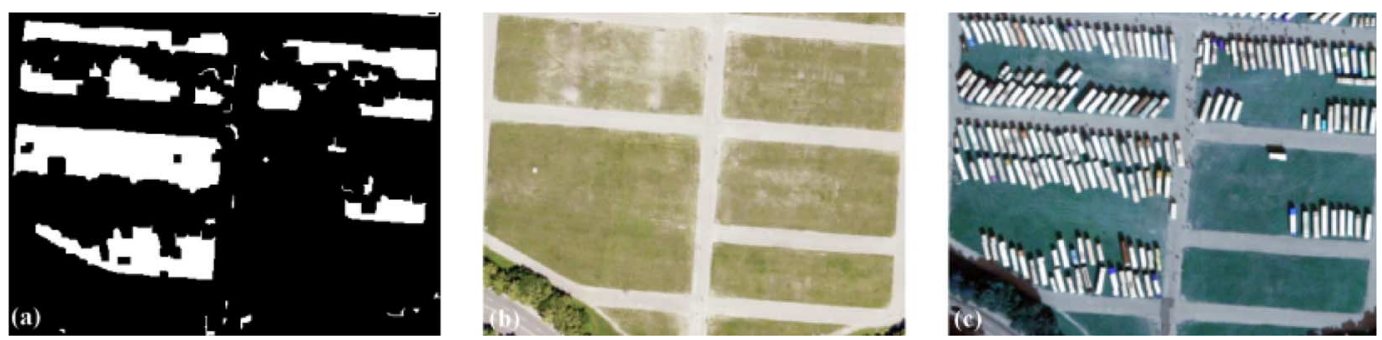

Fig. 19. Subset of the area in Munich: (a) Result of change detection (black: no change, white: change), (b) image taken before the Oktoberfest and (c) image taken during the Oktoberfest.

more than $90 \%$ of the unchanged buildings could be correctly identified. The next steps will involve the inclusion of building information which is stored in GIS or cadastral databases (if available). Also, other more robust segmentation algorithms will be tested for the combined method.

\section{REFERENCES}

[1] P. Coppin, I. Jonckheere, K. Nackaerts, B. Muys, and E. Lambin, "Digital change detection methods in ecosystem monitoring-A review," Int. J. Remote Sens., vol. 25, pp. 1565-1596, Sep. 2004.

[2] A. Singh, "Digital change detection techniques using remote-sensed data," Int. J. Remote Sens., vol. 10, pp. 989-1003, Oct. 1989.

[3] R. D. Macleod and R. G. Congalton, "A quantitative comparison of change-detection algorithms for monitoring eelgrass from remotely sensed data," Photogramm. Eng. Remote Sens., vol. 64, pp. 207-216, Mar. 1998.

[4] J.-F. Mas, "Monitoring land-cover changes: A comparison of change detection techniques," Int. J. Remote Sens., vol. 20, pp. 139-152, Jan. 1999.

[5] D. Lu, P. Mausel, E. Brondízio, and E. Moran, "Change detection techniques," Int. J. Remote Sens., vol. 25, pp. 2365-2407, Dec. 2003.

[6] J. Im, J. R. Jensen, and J. A. Tullis, "Object-based change detection using correlation image analysis and image segmentation," Int. J. Remote Sens., vol. 29, pp. 399-423, Feb. 2008.

[7] S. Khorram, G. S. Biging, N. R. Chrisman, D. R. Colby, R. G. Congalton, and J. E. Dobson, "Accuracy assessment of remote sensing derived change detection," in Amer. Soc. Photogramm. Remote Sens., Bethesda, MD, 1999.

[8] A. Prakash and R. P. Gupta, "Land-use mapping and change detection in a coal mining area-A case study in the Jharia coalfield," Int. J. Remote Sens., vol. 19, pp. 391-410, Mar. 1998.

[9] X. Dai and S. Khorram, "Remotely sensed change detection based on artificial neural networks," Photogramm. Eng. Remote Sens., vol. 65, pp. 1187-1194, Oct. 1999.

[10] G. M. Foody, "Monitoring the magnitude of land-cover change around the southern limits of the Sahara," Photogramm. Eng. Remote Sens., vol. 67 , pp. 841-84, Jul. 2001.

[11] H. Nemmour and Y. Chibani, "Fuzzy neural network architecture for change detection in remotely sensed imagery," Int. J. Remote Sens., vol. 27, pp. 705-717, Apr. 2006.

[12] P. Lohmann, P. Hoffmann, and S. Mueller, J. Schiewe and U. Michel, Eds., "Updating GIS by object-based change detection," Geoinformatics Paves the Highway to Digital Earth: On the Occasion of the 60th Birthday of Professor Manfred Ehlers, vol. 8, pp. 81-86, 2008, gi-reports@igf.

[13] I. Niemeyer and S. Nussbaum, "Automatisierte Detektion, Klassifizierung und Visualisierung von Veränderungen auf der Grundlage von Fernerkundungsdaten," I. Niemeyer, A. Sroka, and R. Wittenburg, Eds., Schriftenreihe des Institutes für Markscheidewesen und Geodäsie an der Technischen Universitaet Bergakademie Freiberg: Tagungsband des 7. Geokinematischen Tages vom 11. und 12. Mai 2006 in Freiberg, Essen: Glueckauf, pp. 248-257, May 2006.

[14] J. R. Jensen, Introductory Digital Image Processing: A Remote Sensing Perspective. Englewood Cliffs, NJ: Prentice-Hall, 2005.

[15] G. Bahrenberg, E. Giese, and J. Nipper, Statistische Methoden in der Geographie: Multivariate Statistik. Wiesbaden, Germany: Vieweg+Teubner, 1992, vol. 2.

[16] R. A. Schowengerdt, Remote Sensing: Models and Methods for Image Processing, 3rd ed. Amsterdam, The Netherlands: Elsevier Academic Press, 2007.
[17] S. Nussbaum and G. Menz, Object-Based Image Analysis and Treaty Verification: New Approaches in Remote Sensing-Applied to $\mathrm{Nu}$ clear Facilities in Iran. Dordrecht, The Netherlands: Springer Science+Business Media B.V., 2008.

[18] D. Tomowski, S. Klonus, M. Ehlers, U. Michel, and P. Reinartz, "Change visualization through a texture-based analysis approach for disaster applications," in ISPRS Technical Commission VII Symposium-100 Years ISPRS Advancing Remote Sensing Science, W. Wagner and B. Szekeyk, Eds., Vienna University of Technology, Austria, 2010, vol. XXXVIII, pp. 263-269, Part 7A.

[19] A. A. Nielsen, K. Conradsen, and J. J. Simpson, "Multivariate alteration detection (MAD) and MAF postprocessing in multispectral, bitemporal image data: New approaches to change detection studies," Remote Sens. Environ., vol. 64, pp. 1-19, 1998

[20] E. O. Brigham, FFT Anwendungen. München, Germany: Oldenbourg Verlag, 1997.

[21] M. Ehlers, "Digitale Bildverarbeitung," Hannover: Schriftenreihe des Institutes für Photogrammetrie und Ingenieurvermessungen, Universität Hannover, Germany, 1984

[22] J. W. Cooley and J. W. Tukey, "Raster-An algorithm for machine calculation of complex Fourier series," Mathematics of Computation, vol. 19, pp. 297-301, 1965.

[23] S. Klonus, D. Tomowski, M. Ehlers, U. Michel, and P. Reinartz, "Change Detection mittels Fourieranalysen, Segment-Sowie Texturbasierter Methoden,"vol. 3, gi-reports@igf, 2011.

[24] M. Ehlers and S. Klonus, "Erhalt der spektralen Charakteristika bei der Bildfusion durch FFT basierte Filterung," Photogrammetrie-Fernerkundung-Geoinformation (PFG), vol. 6, pp. 495-506, 2004.

[25] J. Canny, "A computational approach to edge detection," IEEE Trans. Pattern Anal. Mach. Intell., vol. PAMI-8, pp. 679-698, 1986.

[26] R. M. Haralick, K. Shanmugam, and I. Dinstein, "Textural features for image classification," IEEE Trans. Syst., Man, Cybern., vol. SMC-3, pp. 610-621, 1973.

[27] S. W. Myint, "Urban remote sensing," in Urban Mapping With Geospatial Algorithms, Q. Weng and D. A. Quattrochi, Eds. Boca Raton, FL: CRC Press, 2007, pp. 109-136.

[28] K. T. Steinnocher, "Texturanalyse zur detektion von siedlungsgebieten in hochaufloesenden panchromatischen satellitenbilddaten," in AGIT IX, Salzburger Geographische Materialien, Jul. 1997, vol. 26, pp. $143-152$.

[29] M. Ehlers and D. Tomowski, "On segment based image fusion," $\mathrm{Ob}$ ject-Based Image Analysis-Spatial Concepts for Knowledge-Driven Remote Sensing Applications, Springer Lecture Notes in Geoinformation and Cartography, T. Blaschke, S. Lang, and G. Hayes, Eds., pp. 735-754, 2008.

[30] D. Tomowski, M. Ehlers, U. Michel, and G. Bohmann, Objektorientierte Klassifikation von Siedlungsflaechen Durch Multisensorale Fernerkundungsdaten, gi-reports@igf, vol. 3, 2006.

[31] T. Lehmann, W. Oberschelp, E. Pelikan, and R. Repges, Bildverarbeitung für die Medizin: Grundlagen, Modelle, Methoden, Anwendungen. Berlin, Germany: Springer, 1997.

[32] Object-Based Image Analysis-Spatial Concepts for Knowledge-Driven Remote Sensing Applications, Springer Lecture Notes in Geoinformation and Cartography, T. Blaschke, S. Lang, and G. Hay, Eds. Heidelberg, Germany: Springer, 2008.

[33] M. Baatz and A. Schäpe, "Multiresolution segmentation: An optimization approach for high quality multi-scale image segmentation," in Angewandte Geographische Informationsverarbeitung XII, Beiträge zum AGIT-Symposium Salzburg, 2000, pp. 12-23.

[34] N. Otsu, "A threshold selection method from grey level histograms," IEEE Trans. Syst., Man, Cybern., vol. SMC-9, pp. 62-66, 1979. 
[35] High-Resolution Satellite Imagery and the Conflict in Chad and Sudan, AAAS. [Online]. Available: http://shr.aaas.org/geotech/darfur/darfur. shtml (last access: October 25th, 2011)

[36] Eyes On Darfur, Amnesty International. [Online]. Available: http:/ www.eyesondarfur.org/villages.html (last access: October 25th, 2011)

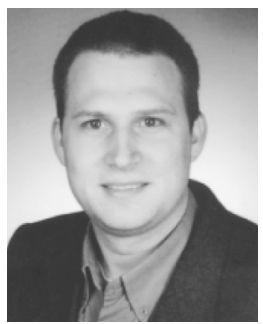

S. Klonus received the $\mathrm{Ph} . \mathrm{D}$. degree from the University of Osnabrueck, Osnabrueck, Germany, in 2011. He received the M.Sc. degree in environmental sciences with focus on geoinformatics from the University of Vechta, Germany, in 2005.

In 2005 and 2006 he worked for the Joint Research Center of the European Commission in the project "Monitoring Agriculture with Remote Sensing". Since 2006 he has been with the Institute for Geoinformatics and Remote Sensing at the University of Osnabrueck. His worked focuses on data fusion, segmentation, change detection and classification.

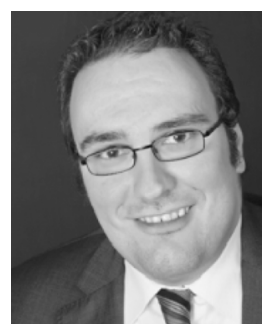

D. Tomowski received the Ph.D. degree from the University of Osnabrueck, Osnabrueck, Germany in 2011. He received the M.Sc. degree in environmental sciences with focus on geoinformatics from the University of Vechta, Germany, in 2006.

From 2006 to 2011 he worked as manager for The Center of Excellence in Geoinformatics in North Germany (GiN), a public-private partnership association and as a scientist at the University of Osnabrueck in different projects. His work focused on change detection, segmentation and classification. Since 2011 he has been responsible for the coordination of research projects at the Technical University of Clausthal.

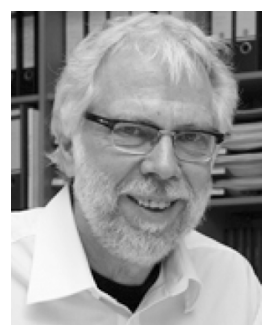

Manfred Ehlers (M'86) is Professor for GIS and Remote Sensing at the University of Osnabrueck, Germany. He is the Director of the University's Institute for Geoinformatics and Remote Sensing. He was the Founding President of the Society for Geoinformatics (a scientific society in Germany, Austria and Switzerland). He is also the Chairman of The Center of Excellence in Geoinformatics in North Germany (GiN), a public-private partnership association. He holds a Master degree in mathematics and a Ph.D. and Habilitation degree (venia legendi) in Surveying Engineering with emphasis on remote sensing, digital image processing and GIS. Dr. Ehlers has published more than 300 papers on digital image processing, remote sensing, Geoinformatics, GIS, mapping, digital photogrammetry, and environmental monitoring and has given over 300 presentations at scientific and professional meetings and conferences. He teaches courses in Geoinformatics, remote sensing, digital image processing, and GIS. His research interests focus on the concepts for integrated geographic analysis and modeling techniques, especially the integration of GIS and remote sensing. Other research areas include geoinformatics concepts, data fusion techniques, and advanced techniques for image analysis. He has been PI or Co-PI for a large number of funded projects in geoinformatics and remote sensing.

Dr. Ehlers is a member of the IEEE Computer Society and IEEE Geoscience and Remote Sensing Society.

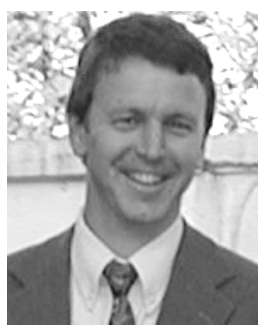

Peter Reinartz received his Diploma (Dipl.-Phys.) in theoretical physics in 1983 from the University of Munich and his Ph.D. (Dr.-Ing.) in civil engineering from the University of Hannover, in 1989. His dissertation was on statistical optimization of classification methods for multispectral image data.

$\mathrm{He}$ is department head of the Photogrammetry and Image Analysis Department, at the German Aerospace Centre (DLR), Remote Sensing Technology Institute (IMF), and holds a Professorship for geoinformatics at the University of Osnabrück. He has more than 25 years of experience in image processing and remote sensing and over 200 publications in these fields. His main interests are in direct georeferencing, stereo-photogrammetry and data fusion of space borne and airborne data, generation of digital elevation models and interpretation of VHR data from sensors like Worldview, GeoEye a.o. He is also engaged in applying remote sensing data for disaster management and using high frequency time series of airborne image data for real time operations in case of disasters as well as for traffic monitoring.

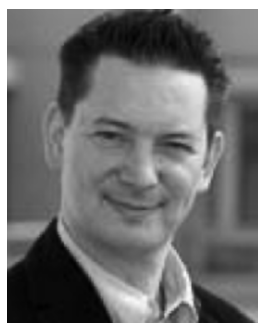

Ulrich Michel received the Ph.D. degree in geoinformatics in 2002 from the University of Vechta, Germany. In 1994 he received his Diploma in geography from the University of Osnabrück, Germany.

He has held academic appointments at various universities and research institutions in Germany and Austria. From 2002 to 2008, he was an Assistant Professor in the field of remote sensing and Geographic Information Systems (GIS) at the Institute for Geoinformatics and Reomote Sensing at the University of Vechta and at the University of Osnabrück. He joined the University of Education Heidelberg, Germany, in 2009, where he is now an Associate Professor for geoinformatics. He teaches courses in GIS, remote sensing and digital geomedia. His research interests focus on the concepts for integration of GIS and remote sensing, change detection technics and mobile GIS. Other research areas include environmental monitoring concepts combining digital geomedia and modern geotools. He is currently the Chairman of the SPIE conference Earth Resources and Environmental Remote Sensing/GIS Applications. 